\title{
Searching for Effective Ways to Implement the Correctional and Pedagogical Process in Pre-School Educational Organizations
}

\author{
Elena Tusheva ${ }^{1, a *}$, Tatyana Ovchinnikova ${ }^{1,2, b}$ \\ 1 Moscow State Pedagogical University, 119991, 1/1 Malaya Pirogovskaya str., Moscow, Russia \\ 2 Leningrad State University named after A. S. Pushkin, 196605, 10 Petersburg highway, St. \\ Petersburg, Russia.
}

atusheva-fps@mail.ru, bots58@inbox.ru

${ }^{*}$ Corresponding author

Keywords: preschool children with impaired development, problems of training and education, algorithm for structuring correctional-pedagogical process, directions for implementation

\begin{abstract}
The article presents a modern analysis of the state of the correctional and pedagogical process and identifies the problems of teaching and educating preschool children with impaired development, which indicated the need to identify effective ways to implement remedial and pedagogical activities in preschool educational organizations. The indications of the block-modular structuring of the correctional-pedagogical process and the filling of diagnostic, methodological, correctional, and cultural-educational blocks with a specific correctional-oriented content. The necessity of developing a comprehensive pedagogical monitoring program aimed at identifying and solving problems in the implementation of the correctional and pedagogical process in a pre-school educational organization is substantiated. Directions in the variable implementation of the correctional and pedagogical process are indicated under the condition of creating a multidimensional adapted educational space with the connection of organizational and methodological modeling of blocks and their components for correctional and developmental tasks and individual characteristics of preschoolers with impaired development.
\end{abstract}

\section{Introduction}

Searching for effective ways of implementing a correctional-pedagogical process in pre-school educational organizations is due to the interpenetration of general, supplementary and remedial education. In new social and educational conditions, an inclusive model of preschool education is a managed educational space, which includes many elements of the mediated interaction of the subject, developmental, and communicative environments. Modern management technologies make it possible to coordinate and change environmental components, thereby ensuring the variability of the educational process and the implementation of differentiated assistance to children, taking into account their educational needs and psychophysical abilities. At the same time, the identity of a child with impaired development is considered as a priority subject who becomes the goal of organizing a barrier-free, adaptive, psychologically safe educational environment that is formed for the full-fledged residence of childhood $[1,2,4,6,8,12]$.

Nevertheless, the emergence of inclusive practices in pre-school educational organization is hampered by still existing contradictions between:

- the presence of a contingent of children with developmental disorders in need of remedial assistance and the degree of preschool organizations' readiness to provide it;

- the need for preschoolers in individually-differentiated training and education and the lack of methodological flexibility of teachers in matters of correctional and pedagogical interaction;

- standardization of preschool education and the possibility of pupils with developmental disabilities to master educational programs without organizational and pedagogical conditions specially created for this.

It is logical to assume that searching effective models for the implementation of the correctional and pedagogical process in a preschool educational organization will contribute to resolving a number of the 
listed contradictions. The readiness of preschool educational organizations for the timely transformation of the components of the educational environment and for its organizational and methodological support can be considered as goal-oriented guidelines in achieving positive results in implementing the correctional and pedagogical process. In this regard, the object of our study is the correctional-pedagogical process carried out in pre-school educational organizations. The subject of the research is focused on searching for effective organizational forms and modification of the content of correctional and developmental education and upbringing of preschool children with impaired development, taking into account the degree of limitation of their viability.

\section{Methods}

A preliminary study of the problem points in the formation of inclusive educational practice made it possible to determine research methods aimed at finding varied forms of organizing the correctionalpedagogical process and changing the content of correctional-developmental education and upbringing of preschool children with impaired development. The selection of methods was due to the highly specialized selection of information necessary to monitor the results of our research. In accordance with the stated theme, targets, the object and subject of research, the methods of searching for effective ways of implementing the correctional and pedagogical process in preschool educational organizations were:

- the study of the contingent of pupils of preschool educational organizations and the identification of risk factors arising in the process of training, education, and socialization of preschool children with developmental disorders;

- analyzing the structure of the correctional and pedagogical process carried out in pre-school organizations;

- determination of effective directions for the implementation of the correctional and pedagogical process in pre-school educational organizations.

\section{Research}

The legal framework for the implementation of the correctional and pedagogical process in pre-school educational organizations consists of:

- Federal Law of the Russian Federation "On Education in the Russian Federation" N 273-FL (as amended by Federal Laws of 07/05/2013 No. 99-FL, of 07/23/2013 No. 203-FL) [14];

- Order of the Ministry of Education and Science of the Russian Federation of October 17, 2013 No. 1155 "On approval of the federal state educational standard of pre-school education" (registered by the Ministry of Justice of Russia on November 14, 2013, registration No. 30384) [10].

In accordance with these documents, Russia is actively introducing various models of inclusive education for children with developmental disabilities, developing various forms and methods to ensure equal access to education for all students, taking into account the diversity of special educational needs and individual capacities (Clause 27, Article 2, 273-FL). According to modern concepts, children with developmental disabilities are the children "having a lag (distortion) in psychophysical development as a result of impaired activity of one or several analyzers (due to the implementation of the concept of inclusive education of visual, auditory, motor, speech), or due to organic lesion of the central nervous system" [3, p. 5].

The range of differences in the development of children with disabilities is extremely large: from practically normal developing, experiencing temporary and relatively easily avoidable difficulties, to children with irreversible severe damage to the central nervous system. Such an understanding is important for expanding the boundaries of assistance from the inclusion of these children in the complex social space and adaptation to it to educational and professional integration, which allows them to give a full-fledged education and fulfill their needs for professional and personal actualization.

Of particular discussion is the question of the large category of preschool children with disabilities, who do not have pronounced primary deviations in development, but lagging behind the age norm, who are 
in general education groups.

The modern stage of the evolution of special pedagogy in Russia has determined the presence of two leading forms of teaching children with developmental disabilities: teaching and raising children with a pronounced degree of impairment in compensating type of organizations in which comprehensive medical and pedagogical assistance is carried out, while children with subtle developmental disabilities are taught conditions of general developmental organization and receive only targeted correctional assistance of a specialist (speech therapist, defectologist, and psychologist).

Studying the contingent of pupils (21546 children) attending 92 preschool educational organizations in St. Petersburg and Moscow, we were able to establish that in groups of general developmental orientation, along with normally developing peers $(52 \%)$, there are children with functional disabilities in development $(48 \%)$.

The most significant group was preschoolers with speech disorders $(28 \%)$ with a predominance of phonetic-phonemic and linguistic underdevelopment.

In the second largest number, there were children with mental retardation $(11 \%)$, whose psychological and social status often falls into the category of conditionally healthy, because their parents do not regard the peculiarities of their behavior and development from the standpoint of development children as distressed. The etiology of violations may be associated with constitutional factors, chronic somatic diseases, unfavorable social conditions of education, and mainly organic insufficiency of the central nervous system of a residual or genetic nature. In the structure of disorders, signs of a slowdown in the rate of mental development prevail, as well as emotional and personal immaturity, affective behavior, egocentrism, and hysterical reactions. Chronic somatic diseases of heart, kidney, endocrine system are caused by a delay in the development of children's motor and speech functions, as well as the delayed formation of self-care skills, productive, and subject-play activities. The manifestation of stable physical and mental asthenia leads to decreasing performance, and the formation of such personality traits as timidity, fearfulness, anxiety. The long-term impact of stressful factors on a child leads to neurotic and neurosis-like disorders, pathological personality development. The identified problems are not organic in nature; therefore, preschoolers, having specific special educational needs, attend general education groups.

In the subsequent ranking, the number of children with deformities of the musculoskeletal system (hip dislocations, scoliosis, cervical osteochondrosis) was 5\%; visual impairment (amblyopia, strabismus) was noted in $4 \%$ of children. Against the background of the manifestation of their specific educational needs, deviations in the mental development of children were not noted, but they all needed systematic treatment and remedial help [7].

The originality of each category of children with impaired development is determined by their special educational needs, which, according to G. V. Chirkina [15], act as a new parameter of the diagnostic survey when choosing options for correctional and pedagogical influence.

V. I. Lubovsky presented a clear and concise definition of the special educational needs of children with developmental disabilities. He noted, "These are needs in conditions necessary for the optimal realization of current and potential opportunities that a child with developmental deficiencies in the learning process needs" [5, P. 62].

The difficulty of teaching and educating preschoolers with not-pronounced developmental disorders in preschool organizations of a general developmental type is precisely that the teachers of these groups do not take into account certain particularities in the development of these children and their educational opportunities [13]. Intensification of training, an increase in the volume of educational loads, the expansion of the range of additional educational services leads to the aggravation of the difficulties of teaching preschoolers and turns educational activity into a risk factor for their health. Being in general developmental orientation groups, preschoolers with mild developmental disorders need special teachers and psychologists' correctional help, which is not always possible to organize in a timely manner even in urban settings. It should be recognized that raising the issue of educating children according to adapted educational programs is not accepted by parents. Thus, the situation is aggravated in which this category of children, having specific educational needs, finds itself in conditions of ineffective inclusive education and upbringing. 
When preschoolers with developmental disabilities are included in the educational process, their training and education is carried out according to the basic educational program, which has a section called "Correctional Work / Inclusive Education" in the structure or an adapted educational program in accordance with recommendations of the psychological-medical-pedagogical commission. Analyzing the structure of the correctional and pedagogical process carried out in preschool educational organizations shows that the adapted nature of organizing the educational environment is sustained. Today, the pre-school organization is multifunctional, performing traditional teaching and educating activities, as well as developing new (not peculiar to it before) correctional, psychocorrectional, and health-improving functions.

Significant achievements of science and practice can recognize the development of an algorithm for structuring the correctional-pedagogical process and its step-by-step implementation [3, 9, 11]. The structure of the correctional and pedagogical process was developed on the basis of the block-modular design of an adapted correctional and developing environment of an educational organization and is represented by diagnostic, methodological, correctional, and cultural-educational units.

A diagnostic unit is particularly important because it focuses on the method of psychological and pedagogical examination of a child designed to identify an individual level of formation of the main lines of development. The main lines of social, physical, educational, speech and artistic, and aesthetic development of a preschooler are key indicators of the current level of development of a child being examined and the starting point for designing an individual educational development trajectory.

The parameters for assessing a social development line are:

- a degree of formation of preschoolers' ideas in educational areas of knowledge;

- child's attitude to the world, to other people, to himself.

- forms of communication;

- a nature of interaction with adults;

- a nature of interaction with other children;

- ways of learning social experience.

Evaluation of the line of physical development is determined by the parameters that establish:

- a degree of emotional tension and physical activity;

- a level of formation of basic movements (walking, running, jumping);

- development of manual and fine motor skills.

The evaluation parameters of the cognitive developmental line include:

- identification of the level of sensory development;

- a definition of the form of thinking;

- a level of formation of ideas about the world;

- a level of development of substantive actions;

- an ability to design and drawing.

Parameters for assessing speech development include:

- understanding of the spoken language;

- a state of active speech of the child.

Evaluation of the line of artistic and aesthetic development is based on the parameters that determine:

- positive emotions in the process of listening to music;

- reactions to musical timbres, tempos, rhythms enriching preschoolers' auditory experience; 
- perception of fiction and folklore.

Methodical block includes information on the creation of a correctional object-developing environment:

- choosing methods and techniques of correctional didactics;

- developing the content of an individual educational program aimed at realizing child's mental potential in the ways of interaction with the outside world and adults.

In the correctional block, the description of conditions and procedures for conducting remedial classes, the nature of child's interaction with an adult, and lesson plans/summaries are summarized. The priority of correctional and pedagogical work is the socialization of preschoolers with developmental disabilities. In the case of developmental disorders, the success of the socialization process is considered to be the level of formation of universal learning activities that determine child's readiness for schooling, while the socialization of preschoolers with severe intellectual disabilities is aimed at developing children's autonomy in everyday life, mastering their cultural and hygienic skills, and social learning by children experience, joining the work.

The cultural and educational block is directly related to the pedagogical work with parents and close relatives. The main help is in the formation of adequate parent-child relationships, the formation of ideas about the state of the child's psychophysical development, and the future prospects of its development. Having determined the type of position that parents take in relation to the child, they develop tactics of their active inclusion in the process of raising a child. An important place is occupied by individual and group forms of work with parents, specific recommendations: what to read, what toys to play, how to organize child's home space, as well as to observe and record his achievements in the photo album.

When filling each block with content, every component has to be changed in accordance with the set correctional-developing task and individual characteristics of a child. To do this, teachers need to master the basics of organizational and methodological modeling, which is a difficult and not yet solved problem.

To identify the problems in implementing= the correctional and pedagogical process, it is necessary to develop a comprehensive program of pedagogical monitoring, allowing to evaluate:

- psychological and pedagogical conditions for the implementation of the correctional and pedagogical process in preschool educational organizations;

- professional skills of teachers to ensure the socialization and individualization of training and education of preschoolers with developmental disabilities through organizational and methodological modeling;

- conditions for modifying the subject-developing environment and methodological support of the correctional and pedagogical process.

We believe that the education and upbringing of preschoolers with developmental disabilities will be effective in creating a multidimensional educational space, including:

- provision of remedial assistance to all categories of children with developmental disorders;

- using a structuring algorithm of the correctional-pedagogical process and its step-by-step implementation;

- organizational and methodological modeling of blocks and their components for correctional and developmental tasks and individual characteristics of a child with impaired development;

- a comprehensive monitoring program for assessing the quality of the correctional and pedagogical process in pre-school educational organizations.

\section{Conclusion}

Thus, searching for effective models of implementing the correctional and pedagogical process in preschool educational organizations is conditioned by their willingness to respond promptly and flexibly to the 
changing contingent of preschool children with impaired development, and to differentiate the correctional and pedagogical impact taking into account their general and specific educational needs.

The algorithm of block-modular structuring of the correctional-pedagogical process and the filling of diagnostic, methodological, correctional, and cultural-educational blocks with a specific correctionaloriented content reflect modern requirements for the organization of training and education of preschool children with impaired development and contributes to the formation of a multidimensional educational space through organizational and methodological modeling of blocks correctional and pedagogical process and their components of corrective developing objectives and individual characteristics of preschool children with developmental disabilities.

\section{References}

[1] Bgazhnokova, I. M. (2013). Modern trends of correctional pedagogy in the organization of an educational environment for children with severe intellectual disabilities. Psychological and pedagogical correction of intellectual development disorders in children in modern education: Collection of materials of the II All-Russian Scientific and Practical Conference (March 5 - 6, 2013). Moscow, Russia: MGPPU.

[2] Denisova, O. A. (2011). Bulletin of the Leningrad State University named after A. S. Pushkin (Series Pedagogy), 3, pp. 178-186.

[3] Strebeleva, E. A., Belyakova, Yu. Yu., Bratkova, M. V. (2016). Correctional care for young children with an organic lesion of the central nervous system in short-stay groups. Moscow, Russia: INFRA-M.

[4] Levchenko, I. Yu., \& Kiseleva, N. A. (2008). Psychological study of children with developmental disabilities. Moscow, Russia: Publishing House "Knigolyub".

[5] Lubovsky, V. I. (2013). Psychological and pedagogical research, 5, pp. 61-66. Retrieved from http://psyedu.ru/journal/2013/5/Lubovskiy.phtml.

[6] Malofeev, N. N. (2001). Formation and development of the state system of special education in Russia. In D. S. Shilov (Ed.), Basics of Special Education Management: Textbook for students of higher educational institutions (pp. 5-47). Moscow, Russia: Publishing Center "Academy."

[7] Ovchinnikova, T. S. (2011). Bulletin of the Leningrad State University named after A. S. Pushkin (Series Pedagogy), 3, pp. 342-352.

[8] Ovchinnikova, T. S. (2012). Bulletin of the Cherepovets State University, 1(36), pp. 111-115.

[9] Stebeleva, E. A., \& Zakrepigna, A. V. (Eds.) (2013). Special children: variable forms of correctional and educational assistance: Methodological guide. Moscow, Russia: LOGOMAG.

[10] Ministry of Education and Science of the Russian Federation. (2013). Order of the Ministry of Education and Science of the Russian Federation of October 17, 2013 No. 1155 (Moscow) "On approval of the federal state educational standard of pre-school education"; Registered in the Ministry of Justice of the Russian Federation on November 14, 2013; Registration No 30384. Moscow, Russia: Government of Russia.

[11] Ekzhanova, E. A., \& Strebeleva, E. A. (2003). The program of preschool educational institutions of compensating type for children with intellectual disabilities: correctional developmental training and education. Moscow, Russia: Enlightenment.

[12] Tusheva, E. S. (2015). Crede Experto: Transport, Society, Education, Language, 1, pp. 123-129.

[13] Tusheva, E. S. (2016). Studying the transformations of teachers' professionalism in the context of educational integration of children with disabilities. In Materials of the XV International Scientific and Practical Conference "Modernization of the Vocational Education System Based on Regulated Evolution" (Moscow - Chelyabinsk. November 16, 2016). Moscow, Russia. 
[14] Government of Russia. (2013). Federal Law of the Russian Federation "On Education in the Russian Federation" No 273-FL (as amended by Federal Laws of 07/05/2013 No 99-FL, of 07/23/2013 No 203-FL). Moscow, Russia: Government of Russia.

[15] Chirkina, G. V. (2012). Uchenye zapiski: Electronic scientific journal of Kursk State University, 2(22), pp. 45-49. 